\title{
Trend analyses of regional time series of temperatures and rainfall of the Tapi basin
}

\author{
GANESH D. KALE
}

\author{
Civil Engineering Department, Sardar Vallabhbhai National Institute of Technology,Surat-395007, Gujarat \\ E-mail:kale.gd@gmail.com
}

\begin{abstract}
Climate change information at the scale of basin is vital for planning, development and use of water. The Tapi basin is climatically responsive. Hydrological response of a basin is based mainly on rainfall and temperature. Variations in climate at regional scales impacts fundamental features of our life. Thus, in the present work, trend analyses of regional time series (1971-2004) of minimum, mean, maximum temperatures and rainfallis performed for monthly, annual and seasonal scales for the Tapi basin. Correlogram is utilized for evaluation of dependence of data. Mann-Kendall test and Mann-Kendall test with block bootstrapping are applied for the evaluation of trend significance. Sen's slope test is applied for the evaluation of trend magnitude. Sequential Mann-Kendall test is applied for assessment of beginning and end of the trend. Statistically significant positive trends are detected in regional annual and winter $\mathrm{T}_{\text {mean }}$ time series with their beginning in years 1974 and 1972 , respectively.
\end{abstract}

Keywords: Regional time series; three temperatures; rainfall; Tapi basin; trend analyses

Worldwide, climate change poses significant risks throughout thevarious ecosystems (Singh et al., 2019).India is amongst the severely affected countries where the changes in rainfall and temperature have been detected (Panwar et al., 2019).Information about climate change on basin scale is of highest importance for utilization, planning and development of water (Singh et al., 2008a). Bhamare and Agone (2011) observed that, there was an increment in the surface temperature of the Tapi basinlocated in the central part of India by $2^{\circ} \mathrm{C}$ over the period 1990 to 2010 . Deshpande et al.(2016) detected significant increment in maximum and mean temperatures during post-monsoon season for NarmadaTapi basin. They have also detected significant increment in the intensity of heavy rainfall events for Godavari and Narmada-Tapi basins. Thus, these facts show that, Tapi basin is climatically responsive.

Shah and Mishra (2016) studied long-term (19012012) alterations in hydroclimatic variates of eighteen river basins of Indian subcontinent (including the Tapi basin) with hydrology simulated by employing the Variable Infiltration Capacity model. Change point assessment was performed by applying SQMK test and trend in precipitation ( $\mathrm{mm} /$ year) was assessed by using the MK test. Change point analysis had shown two distinct periods (1901 to 1947 and 1948 to 2012) for domain averaged monsoon precipitation. During 1901 and 1947, a notable increase was noticed in monsoon precipitation of the Tapi basin and six other basins too. During period 1948-2012 and 1975-2012, increasing trend was found in air temperature of the Tapi basin for monsoon season but it was not significant.

Hence, the present study has been proposed to address the research gap by performing trend analyses of regional time series of temperatures and rainfall of the Tapi basin by: 1) using innovative trend analysis plot and smoothing curve for aiding results of trend analyses, 2) assessing beginning and end of trend by using SQMK test (if present in time series), 3) using Sen's slope (SS) test for the assessment of trend magnitude and 4) simultaneous evaluation of trend significance, trend magnitude, beginning and end of trend and pattern of trend. Sen (1968) had given that, SS estimator is more robust to outliers than least square estimator.

\section{MATERIALS AND METHODS}

The Tapi basin extends from Multai Reserve forest located in the Madhya Pradesh's Betul district. The basin is spread over three states of India i.e. Gujarat, Maharashtra and Madhya Pradesh. Area of the basin is $65145 \mathrm{~km}^{2}$. Maximum width and length of basin are 196 and $534 \mathrm{~km}$, respectively. The basin is located between longitudes $72^{\circ} 33^{\prime}$ E to $78^{\circ} 17^{\prime} \mathrm{E}$ and latitudes $20^{\circ} 9^{\prime}$ ' $\mathrm{N}$ to $21^{\circ} 50^{\prime} \mathrm{N}$ in the Deccan Plateau. On the north, the basin is bounded by the Satpura range and on the south by Ajanta range and Satmala hills. Of the total area of basin, $66.19 \%$ area is used for the agriculture. Water bodies cover about $2.99 \%$ of the basin. Average water 


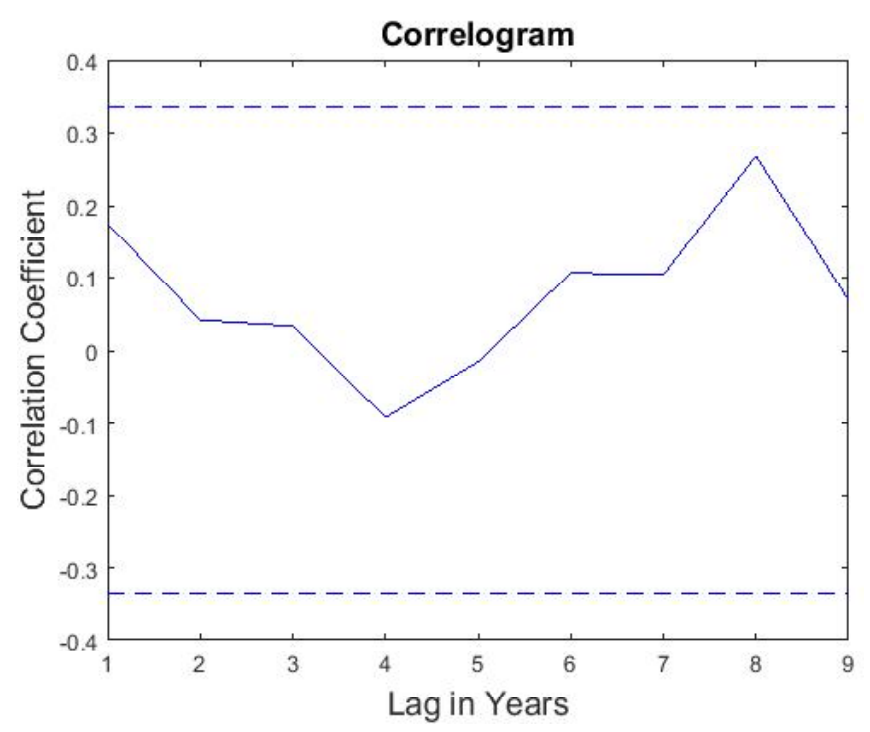

Fig.1:Correlogram of regional annual $\mathrm{T}_{\text {mean }}$ time series

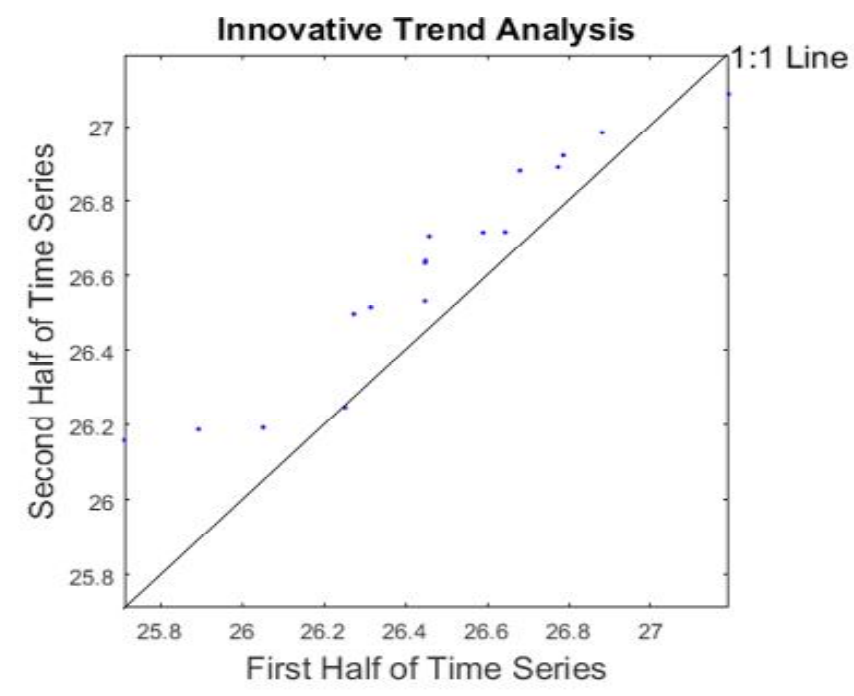

Fig.3:ITA plot of regional annual $\mathrm{T}_{\text {mean }}$ time series

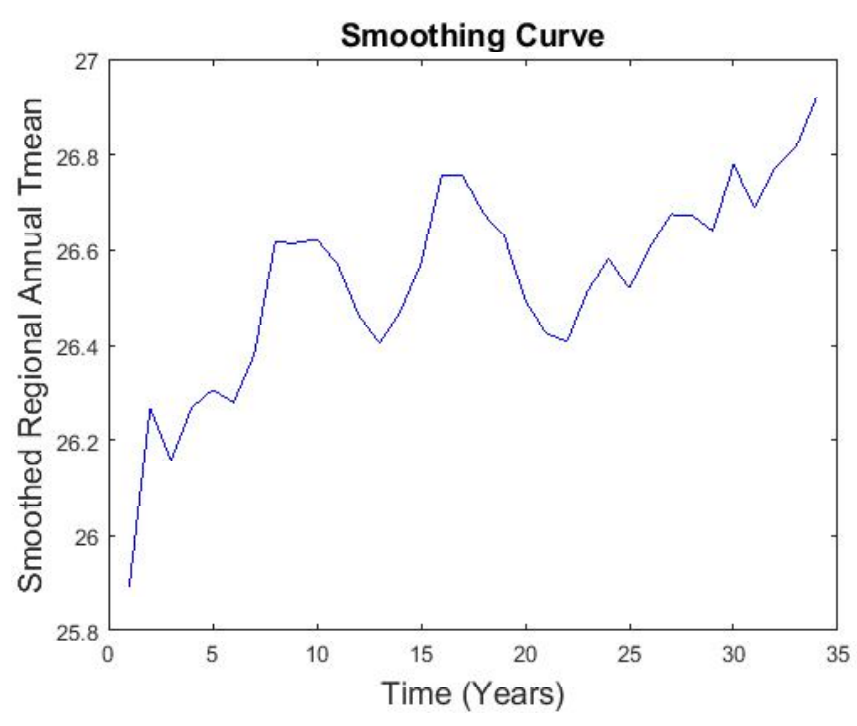

Fig.2: Smoothing curve of regional annual $\mathrm{T}_{\text {mean }}$ time series

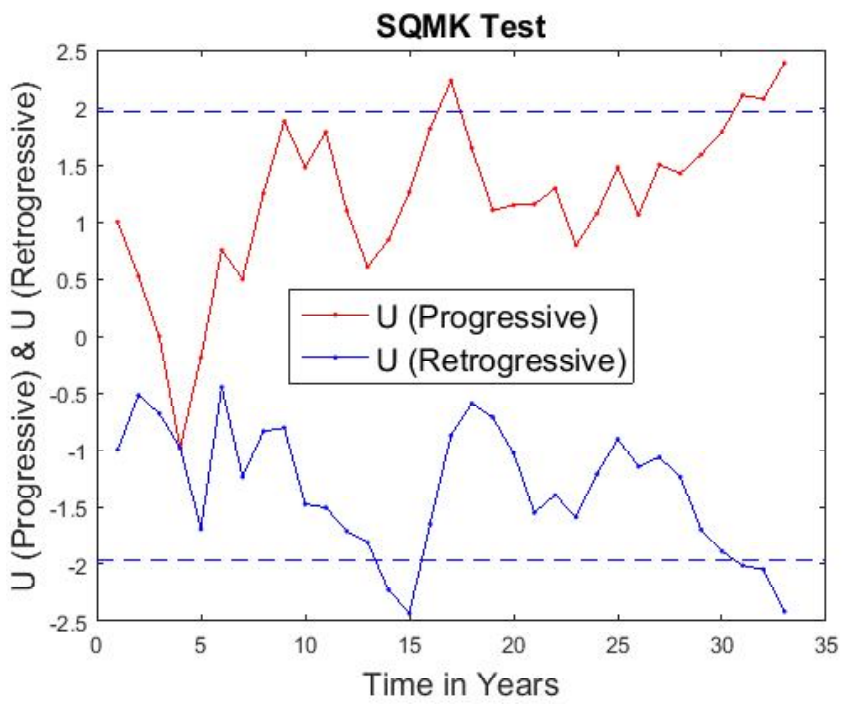

Fig.4: Progressive $u(t)$ and retrogressive $u^{\prime}(t)$ time series plots of SQMK test for regional annual $\mathrm{T}_{\text {mean }}$

Table 1: Results of trend analyses of regional temperature and rainfall time series of all temporal scales.

\begin{tabular}{lcccccc}
\hline Statistical Test & Annual & Monthly & Winter & Pre-Monsoon & Monsoon & Post-Monsoon \\
\hline $\mathrm{T}_{\min }$ MK & - & - & - & 0 & 0 & 0 \\
MKBBS & 0 & 0 & 0 & - & - & - \\
$\mathrm{T}_{\max } \mathrm{MK}$ & - & - & 0 & - & 0 & - \\
MKBBS & 0 & 0 & - & 0 & - & 0 \\
$\mathrm{~T}_{\text {maan }}$ MK & 1 & - & 1 & - & 0 & 0 \\
MKBBS & - & 0 & - & 0 & - & - \\
Rainfall MK & 0 & - & 0 & 0 & 0 & - \\
MKBBS & - & 0 & - & - & - & 0 \\
\hline
\end{tabular}


resource potential of thebasin is 14,880 million cubic metre (MCM) (http://india-wris.nrsc.gov.in/wrpinfo/ index.php?title=Tapi "last accessed on September 09, 2018).

\section{Data}

Minimum, mean and maximum temperatures data of the Tapi basin are taken up for the analysis in the present study. For this purpose, Climate Research Unit Timeseries (CRU TS) 3.22 data (1901-2013) of $\mathrm{T}_{\text {min }}, \mathrm{T}_{\text {mean }}$ and $\mathrm{T}_{\max }$ temperatures is downloaded. These data are monthly gridded data of $0.5^{0} \times 0.5^{0}$ lat/lon grids. The CRU TS 3.22 data is available at "http://www.cru.uea.ac.uk/cru/data/hrg/ cru_ts_3.22/" ("last accessed on September01, 2018”). The time period of analysis for three parameters (minimum, mean and maximum) of the basin is 1971-2004.

The seasons used in the analyses are:1) winter (January, February), 2) pre-monsoon (March to May), 3) monsoon (June to September) and 4) post-monsoon (October to December), as adopted in Sonali and Nagesh Kumar (2013).

Temperature values for each month over all grids (over the basin) are averaged to get the regional monthlyvalue for corresponding month and regional monthly time series is obtained subsequently, which is used in the preparation of regional annual and regional seasonal time series.

Rainfall data of $0.5^{0} \times 0.5^{0}$ lat $/$ lon resolution for the Indian region was obtained for the period, 1971-2005, from India Meteorological Department (IMD), Pune.From year 1971, data of rainfall was available, which is common available starting year amidst data of three temperatures and rainfall of the Tapi basin.

\section{Methodology}

Series slope test (Sen, 1968; Sonali and Nagesh Kumar, 2013)was used for analyzing magnitude of the trend. The autocorrelation plot or correlogram was utilized, for the evaluation of dependence of the data.

For the independent data, statistical significance of the trend was evaluated by applying MK test.Block bootstrapping (BBS) approachwith MK test called MKBBS test(Kale and Nagesh Kumar, 2018; Khaliq et al., 2009) was used for evaluation of statistical significance of trend for the dependent data. The sequential version of MK could be contemplated as an efficacious way of locating the starting year(s) of a trend (Partal and Kahya, 2006). Similarly, last point of intersection will indicate end of trend (Kale, 2016).
Thus, beginning and end of trend (if present in given time series) was assessed by using SQMK test.

ITA plot is used for identification of monotonous trend, otherwise a combination of different trends or presence of trend free portions in the time series (Sen, 2012). A smoothing curvecan assist interpretation by accentuating the general association among the variables (Kundzewicz and Robson, 2000). Thus, smoothing curve is used in the present study. ITA plot and smoothing curve give support to the result of trend analysis.

\section{RESULTS AND DISCUSSION}

Trend analyses of regional time series (1971-2004) of temperatures and rainfall was performed for six temporal scales viz. monthly, annual and seasonal.Correlogram, smoothing curve, ITA plot and progressive $u(t)$ and retrogressive $u^{\prime}(t)$ time series plots of SQMK test are presented only for regional annual $\mathrm{T}_{\text {mean }}$ time series in which statistically significant trend is detected, because of space restrictions.

The time series (1971-2004) of minimum temperature $\left(\mathrm{T}_{\min }\right)$, maximum temperature $\left(\mathrm{T}_{\max }\right)$ and rainfall of Tapi basin corresponding to all temporal scales have not shown statistically significant trends on application of MK and MKBBS tests. ' 0 ' indicates absence and ' 1 ' indicate presence of statistically significant trend (Table 1), while the mean temperature $\left(\mathrm{T}_{\text {mean }}\right)$ has shown non significant in monthly, premonsoon, monsoon and post monsoon season. It was significant only on annual scale as well as in winter season.

Correlogram of regional annual $\mathrm{T}_{\text {mean }}$ time series for the period 1971-2004 is shown in Fig. 1, smoothing curve is shown in Fig.2, ITA plot is shown in Fig. 3 and progressive $\mathrm{u}(\mathrm{t})$ and retrogressive $\mathrm{u}^{\prime}(\mathrm{t})$ time series plots of the SQMK test are shown in Fig.4. Correlogram in Fig.1 shows that, regional annual $\mathrm{T}_{\text {mean }}$ time series data is independent, therefore $\mathrm{MK}$ test is applied to the corresponding time series.

Statistically significant increasing (positive) trend in regional annual $\mathrm{T}_{\text {mean }}$ time series for the period 1971-2004 is supported by increasing pattern of data present in corresponding smoothing curve and ITA plot as shown in Fig. 2 and 3, respectively.

Magnitude of trend in regional annual $\mathrm{T}_{\text {mean }}$ time series is $0.013{ }^{\circ} \mathrm{C} /$ year as evaluated by the SS test whilst nature of the trend is non-monotonous (increasing and decreasing) as assessed by the ITAplot (Fig. 3). Trend in regional annual $\mathrm{T}_{\text {mean }}$ time series begins in 1974 as assessed by the SQMK test and graphical result of the SQMK test is 
shown in Fig. 4.

Magnitude of trend in regional winter $\mathrm{T}_{\text {mean }}$ time series is $0.023{ }^{0} \mathrm{C} /$ year as evaluated by the $\mathrm{SS}$ test, whilst nature of the trend is monotonically increasing as assessed by the ITA plot. Trend in regional winter $\mathrm{T}_{\text {mean }}$ time series begins in 1972 and ends in 1975 as assessed by the SQMK test.

Although nature of the trend in regional annual $\mathrm{T}_{\text {mean }}$ time series is non-monotonous (increasing and decreasing) but it is dominantly increasing, which supports positive value of SS. On the other hand, nature of the trend in regional winter $\mathrm{T}_{\text {mean }}$ time series is monotonically increasing, which also supports positive value of SS.

\section{CONCLUSIONS}

Trend analyses of regional time series (1971-2004) of temperatures and rainfall showed statistically significant positive trends in regional annual and regional winter $\mathrm{T}_{\text {mean }}$ time series and if the same trends persist in future,then evaporation will increase in the Tapi basin resulting into decrease in the streamflow of the basin in corresponding temporal scales.

\section{ACKNOWLEDGEMENTS}

Author is thankful to India-WRIS Project, Climate Research Unit, UK and India Meteorological Department, Pune from which necessary information and data are collected, which are used in the present study. Author is also thankful to Dr. D. Nagesh Kumar, Professor in Department of Civil Engineering, Indian Institute of Science, Bengaluru, Karnataka, India.

\section{REFERENCES}

Bhamare, S.M. and Agone, V. (2011). Change detection of surface temperature and its consequence

using multi-temporal remote sensing data and GIS application to Tapi basin of India. In: Proceedings of the Global Conference on Global Warming, Lisbon, Portugal, p. 112.

Deshpande, N.R., Kothawale, D.R., and Kulkarni, A. (2016). Changes in climate extremes over major river basins ofIndia. Int. J.Climatol., 36:4548-4559.
Kale, G.D. (2016). Detection of Trends in Rainfall of Homogeneous Regions and Hydro-Climatic

Variables of Tapi Basin With Their Attribution. (Doctoral Dissertation, Indian Institute of Science, Bangalore, Karnataka, India).

Kale, G.D., and Nagesh Kumar, D. (2018). Trend detection analysis of seasonal rainfall of homogeneous regions and all India, prepared byusing individual month rainfall values. Water Conserv. Sci. Eng., 3(2):129-138.

Khaliq, M.N., Ouarda, T.B.M.J., Gachon, P., Sushama, L., and St-Hilaire,A. (2009). Identification of hydrological trends in the presence of serial and cross correlations: a review of selected methods and their application to annual flow regimes of Canadian rivers. J. Hydrol., 368:117-130.

Kundzewicz, Z.W., and Robson, A.J. (2000).Detecting Trend and OtherChanges in Hydrological Data. World Climate Programme Data and Monitoring, WMO/TD-No. 1013

Panwar, P., Pal, S., Loria, N., Verma, M.R., Alam, N.M., Bhatt, V.K., Sharma, N.K., and Mishra, P.K. (2019). Variability and time series trends of rainfall and temperature in Indian Himalaya. J. Agrometeorol., 21(2):220-223.

Partal, T., and Kahya, E. (2006). Trend analysis in Turkish precipitation data. Hydrol. Process., 20:2011-2026.

Sen, P.K. (1968). Estimates of regression coefficient based on Kendall's tau.J.American Stat. Assoc., 63(324):13791389.

Sen, Z. (2012). Innovative trend analysis methodology. $J$. Hydrol. Eng., ASCE, 17(9):1042-1046.

Shah, H.L., and Mishra, V. (2016). Hydrologic changes in Indian subcontinental river basins(1901-2012). J. Hydrometeor., 17:2667-2687.

Singh, P., Kumar, V., Thomas, T., andArora, M.(2008a). Changes in rainfall and relative humidityin river basins in northwest and central India. Hydrol. Process., 22:2982-2992.

Sonali, P., and Nagesh Kumar, D. (2013). Review of trend detection methods and their application to detect temperature changes in India. J. Hydrol., 476:212-227. ht t p : / india-wris.nrsc.gov.in/wrpinfo/ index.php?title=Tapi http://www.cru.uea.ac.uk/cru/ $\mathrm{data} / \mathrm{hrg} / \mathrm{cru}$ ts_3.22/CRU TS Version 3.22 